\title{
Fatal Ischaemic Stroke During COVID-19 and Acute Lung Injury
}

\author{
Iris Duroi ${ }^{1}$, Frederik Van Durme ${ }^{1}$, Tony Bruyns ${ }^{2}$, Sofie Louage ${ }^{2}$, Alex Heyse $^{1}$ \\ ${ }^{1}$ Department of Cardiology, AZ Glorieux, Ronse, Belgium \\ ${ }^{2}$ Department of Anesthesiology, AZ Glorieux, Ronse, Belgium
}

Received: 18/05/2020

Accepted: $19 / 05 / 2020$

Published: $26 / 05 / 2020$

How to cite this article: Duroi I, Van Durme F, Bruyns T, Louage S, Heyse A. Fatal ischaemic stroke during COVID-19 and acute lung injury. EJCRIM 2020;7: doi:10.12890/2020_001732.

Conflicts of Interests: The Authors declare that there are no competing interests.

This article is licensed under a Commons Attribution Non-Commercial 4.0 License

\section{ABSTRACT}

Severe COVID-19 may predispose to both venous and arterial thrombosis. We describe a patient with acute ischaemic stroke while suffering from COVID-19 and respiratory failure, necessitating mechanical ventilation. Deep sedation may delay diagnosis.

\section{LEARNING POINTS}

- A thrombotic stroke can complicate severe COVID-19.

- Prolonged deep sedation during mechanical ventilation of COVID-19 patients may delay the diagnosis of stroke.

- The hypercoagulability and a thrombo-inflammatory response in COVID-19 is characterized by an increase in D-dimers and fibrinogen.

\section{KEYWORDS}

COVID-19, stroke, acute respiratory distress syndrome, ARDS, thrombosis

\section{INTRODUCTION}

Neurological problems in patients with severe coronavirus disease 2019 (COVID-19) are common, varying from encephalopathy, confusion and agitation, to acute stroke ${ }^{[1]}$. Here, we report a fatal ischaemic stroke in a patient with severe COVID-19 complicated by acute respiratory distress syndrome (ARDS).

\section{CASE DESCRIPTION}

A 74-year-old woman without a medical history and without cardiovascular risk factors was admitted to the emergency department because of desaturation documented by the general practitioner. She had had fever and a dry cough without dyspnoea for 7 days. Clinical examination was normal without tachypnoea. The transcutaneous oxygen saturation was $91 \%$ breathing room air. Laboratory examination revealed a normal white cell count $\left(9700 / \mathrm{mm}^{3}\right.$, normal value $\left.3500-11,000 / \mathrm{mm}^{3}\right)$ with low but still normal lymphocytes $\left(1040 / \mathrm{mm}^{3}\right.$, normal value $1000-4800 / \mathrm{mm}^{3}$ ), elevated C-reactive protein (187.9 mg/l, normal value $\left.0-5 \mathrm{mg} / \mathrm{l}\right)$, elevated procalcitonin (1.93 ng/ml, normal value $<0.25 \mathrm{ng} / \mathrm{ml})$, elevated ferritin (846.1 $\mu \mathrm{g} / \mathrm{l}$, normal value $11-306.8 \mu \mathrm{g} / \mathrm{l})$ and a mildly increased creatinine (1.02 mg/dl, normal value 0.51 $0.95 \mathrm{mg} / \mathrm{dl})$. D-dimers were not determined on admission but were elevated 2 days later ( $2504 \mathrm{ng} / \mathrm{ml}$, normal value 0-500 ng/ml). Sinus rhythm was noted on the electrocardiogram in addition to a QTc interval of $433 \mathrm{msec}$. A chest x-ray showed bilateral pneumonia (Fig. 1). The diagnosis of COVID-19 was confirmed by polymerase chain reaction on a nasopharyngeal swab.

The patient was hospitalized and treated with low-flow oxygen via a nasal cannula, oral hydroxychloroquine (400 mg twice on the first day, $200 \mathrm{mg}$ twice on days 2-5) and subcutaneous enoxaparin (40 mg once daily). Intravenous amoxicillin/clavulanic acid (1 g/200 mg every 6 hours) was administered because of the possibility of concomitant bacterial infection. 


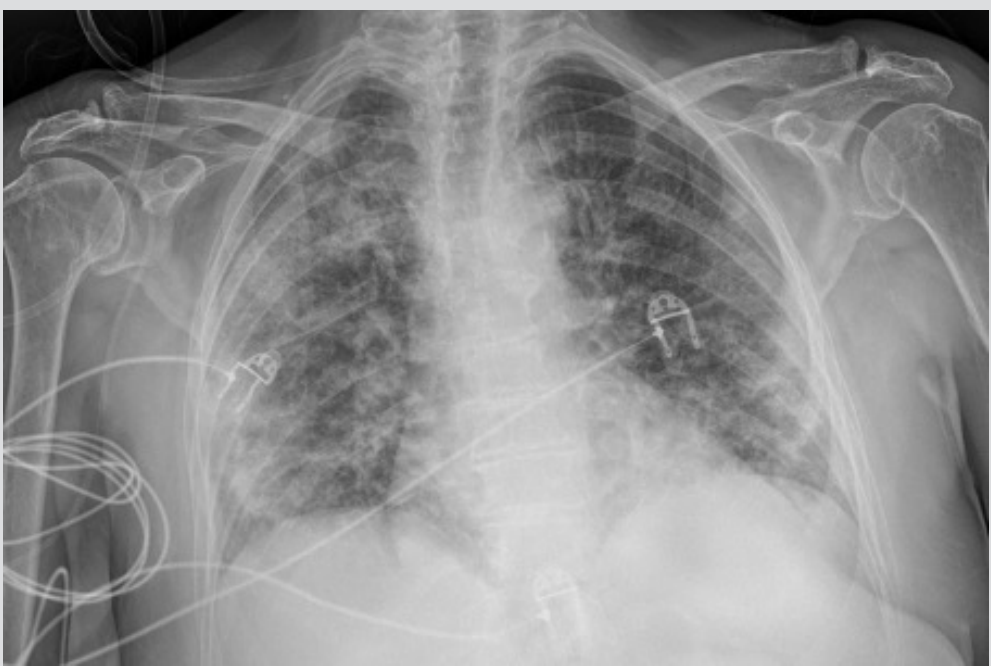

Figure 1. Chest $x$-ray on admission showing bilateral opacities

Unfortunately, the patient developed hypoxic respiratory failure necessitating a transfer to the intensive care department where she was intubated on the 3rd hospital day. She was mechanically ventilated and sedated with midazolam, piritramide and dexmedetomidine without the need for neuromuscular blockade. The maximal fraction of inhaled oxygen $\left(\mathrm{FiO}_{2}\right)$ was $60 \%$ with a partial arterial pressure of oxygen $\left(\mathrm{PaO}_{2)}\right.$ of $57 \mathrm{mmHg}$ leading to a $\mathrm{PaO}_{2} / \mathrm{FiO}_{2}$ ratio of $95 \mathrm{mmHg}$, consistent with the diagnosis of severe ARDS. On day 7 , the dose of enoxaparin was increased to $40 \mathrm{mg}$ twice a day $(0.5 \mathrm{mg} / \mathrm{kg}$ twice a day) based on new insights into hypercoagulability in COVID-19 patients. On the 10th hospital day, the patient developed hypertension, which was treated with intravenous nicardipine. Because of decreasing oxygen demands, the weaning process was started on the 13th hospital day and she was finally extubated on day 16 . She remained unconscious although she was breathing without assistance. At that moment a mild endorotation of the arms was documented. A computed tomography (CT) scan was performed showing a large infarct with hypodensity in the territory of the middle cerebral artery in addition to oedema and deviation of the midline (Fig. 2). At the transition of the left internal carotid artery to the origin of the middle cerebral artery, a hyperdense artery sign was seen due to a thrombotic occlusion (Fig. 3).

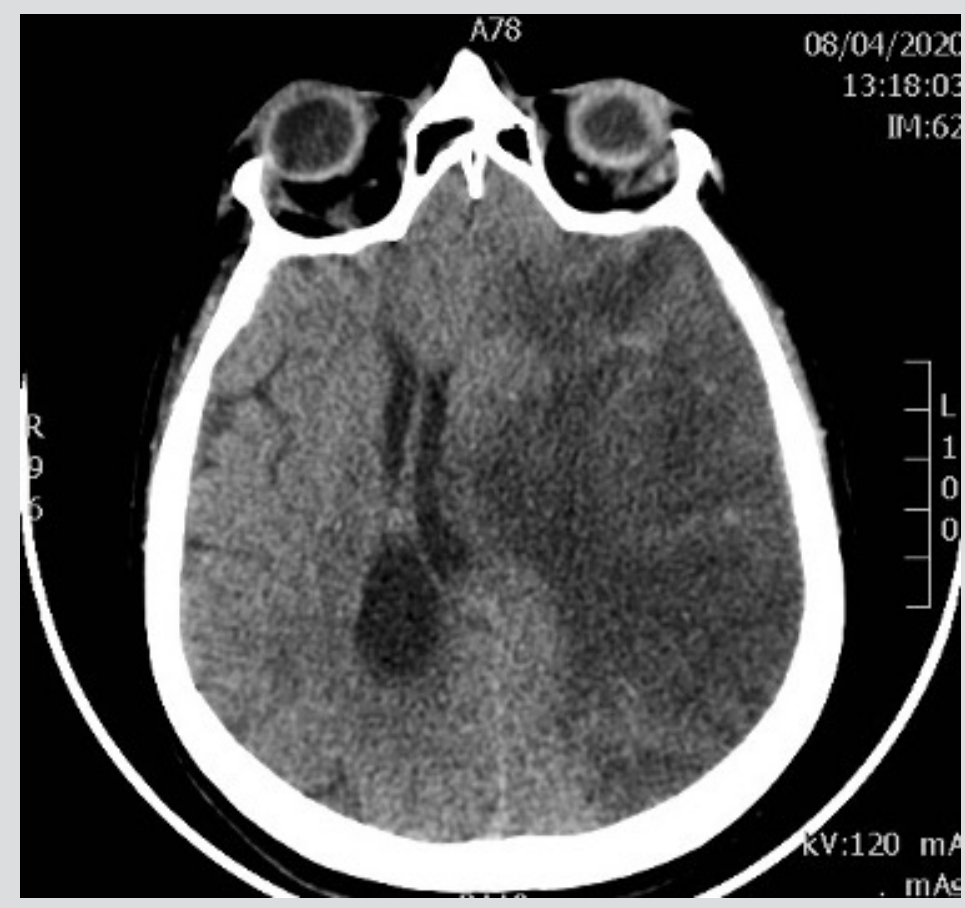

Figure 2. CT scan of the brain showing a large infarct with hypodensity in the territory of the middle cerebral artery in addition to oedema and midline shift 


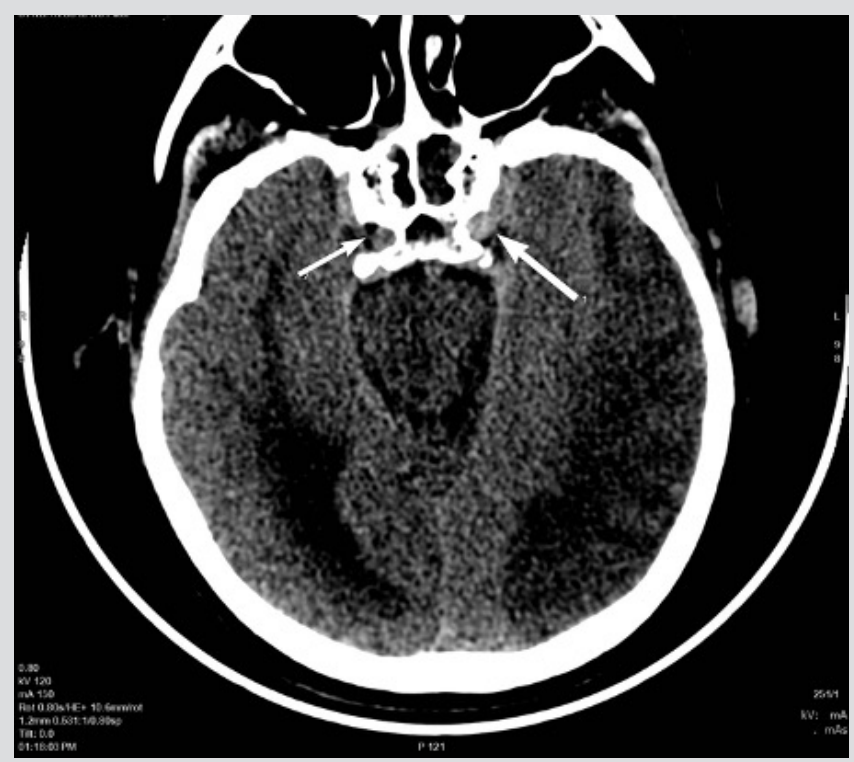

Figure 3. CT scan showing a hyperdense artery sign in the sellar region (large arrow) at the transition of the left internal carotid artery to the origin of the middle cerebral artery compared with patent vessels on the right (small arrow)

The platelet count and prothrombin time were normal. D-dimers (3941 ng/ml, normal value 0-500 ng/ml) and fibrinogen (606 mg/dl, normal value $170-420 \mathrm{mg} / \mathrm{dl}$ ) were both elevated. No episodes of atrial fibrillation were documented during hospitalization. A transthoracic echocardiography showed normal left ventricular function and did not reveal a cardiac source of the thrombus. There was no evidence for venous thrombosis and although a transesophageal echocardiography was not performed, a paradoxical embolism was deemed unlikely. A decision to implement palliative treatment was taken and the patient died the same day. Additional laboratory testing revealed no antiphospholipid syndrome and no thrombophilia.

\section{DISCUSSION}

The link between severe COVID-19 and increased risk from venous thromboembolism is well established [2]. COVID-19 may predispose to both venous and arterial thrombosis, potentially due to excessive inflammation and hypercoagulability ${ }^{[3]}$. There are several reports of acute ischaemic stroke in patients with COVID-19 ${ }^{[4,5]}$. We report a fatal ischaemic stroke due to thrombotic occlusion of the left carotid artery without an apparent cardiac cause. The patient did not have heparin-induced thrombopenia, antiphospholipid syndrome, thrombophilia or acute disseminated intravascular coagulation. COVID-19 with acute lung injury is associated with hypercoagulability and a thromboinflammatory response, characterized by an increase in D-dimers and fibrinogen, translating clinically to a tendency towards increased thrombosis ${ }^{[6]}$. Our hypothesis is a thrombotic stroke was triggered by severe inflammation during severe COVID-19. The stroke may have occurred after 1 week of ventilation when the patient became hypertensive. Deep sedation during prolonged ventilation probably delayed the clinical detection of stroke.

In conclusion, we have described the occurrence of thrombotic stroke as a potential complication of severe COVID-19 with respiratory failure and mechanical ventilation.

\section{REFERENCES}

1. Helms J, Kremer S, Merdji H, Clere-Jehl R, Schenck M, Kummerlen C, et al. Neurologic features of severe Sars-CoV2 infection. N Engl J Med 2020 Apr 15. doi: 10.1056/ NEJMc2008597 [Epub ahead of print].

2. Tavazzi G, Civardi L, Caneva L, Mongodi S, Mojoli F. Thrombotic events in SARS-CoV2 patients: an urgent call for ultrasound screening. Intensive Care Med 2020 Apr 22 . doi: 10.1007/s00134-020-06040-3 [Epub ahead of print].

3. Klok FA, Kruip MJHA, van der Meer NJM, Arbous MS, Gommers D, Kant KM, et al. Incidence of thrombotic complication in critically ill ICU patients with COVID-19. Thromb Res 2020 Apr 10. pii: S0049-3848(20)30120-1. doi:10.1016/j.thromres.2020.04.013 [Epub ahead of print].

4. Mao L, Jin H, Wang M, Hu Y, Chen S, He Q, et al. Neurologic manifestations of hospitalized patients with coronavirus disease 2019 in Wuhan, China. JAMA Neurol 2020 Apr 10. doi: 10.1001/jamaneurol.2020.1127 [Epub ahead of print].

5. Oxley T, Mocco J, Majidi S, Kellner CP, Shoirah H, Singh IP, et al. Large-vessel stroke as presenting feature of Covid-19 in the young. N Engl J Med 2020 Apr 28. doi: 10.1056 NEJMc2009787 [Epub ahead of print].

6. Ranucci M, Ballota A, Di Dedda U, Bayshnikova E, Dei Polli M, Resta M, et al. The procoagulant pattern of patients with COVID-19 acute respiratory distress syndrome. J Thromb Haemost 2020 Apr 17. doi: 10.1111/jth.14854 [Epub ahead of print]. 